\title{
Panorama da Síndrome Inflamatória Multissistêmica Pediátrica associada à Covid-19 (SIM-P) em crianças da região amazônica
}

\author{
Overview of Pediatric Multisystemic Inflammatory Syndrome associated with Covid-19 \\ (SIM-P) in children from the Amazon region
}

\section{Introducción al síndrome inflamatorio multisistémico pediátrico asociado con Covid-19 (SIM-P) en niños de la región amazónica}

Ana Carolina Costa Macedo ${ }^{1 *}$, Érica Gomes do Nascimento Cavalcante ${ }^{2}$, Caroline Cunha da Rocha $^{1}$, Maria Josiane Brito Silva ${ }^{1}$, Denise Rezende Travessa ${ }^{2}$, Eliana Canen Pinto Soares ${ }^{2}$.

\section{RESUMO}

Objetivo: Descrever os achados laboratoriais e as características clínico-epidemiológicas em crianças e adolescentes com Síndrome Inflamatória Multissistêmica Pediátrica (SIM-P) associada à COVID-19 atendidas em hospital na região amazônica. Métodos: Trata-se de um estudo transversal, quantitativo, retrospectivo, com dados de 28 pacientes, de ambos os sexos, atendidos entre abril e agosto de 2020, coletados através da análise de prontuários, usando ficha de coleta de dados adaptada, considerando aspectos clínicos, epidemiológicos e laboratoriais. As estatísticas descritiva e analítica, foram realizadas no software BioEstat® 5.320. Após, aprovação deste pelo Comitê de Ética em Pesquisa. Resultados: A amostra teve com média de idade de 4,9 anos \pm 5 anos, sem predomínio entre os sexos. Os principais sinais e sintomas encontrados foram dispneia, náusea/vômito, dor abdominal, tosse, coriza, edema de mãos e pés, e diarreia. Entre as alterações laboratoriais verificou-se elevação de troponina (100\%), de D-Dímero, de VHS (96\%), hipertrigliceridemia (95\%), queda da hemoglobina (96\%), decréscimo do HDL (81\%), elevação do TGP (76,9\%) e da ferritina (76,9\%). Conclusão: Conclui-se não haver predomínio entre os sexos, com faixa etária ampla, sendo as manifestações clínicas mais frequentes as respiratórias e gastrointestinais. Os principais achados laboratoriais refletem alta atividade inflamatória e o caráter sistêmico da doença.

Palavras-chave: Coronavírus, Infecção por coronavírus, Síndrome de resposta inflamatória sistêmica.

\begin{abstract}
Objective: To describe laboratory findings and clinical-epidemiological characteristics in children and adolescents with Pediatric Multisystemic Inflammatory Syndrome (SIM-P) associated with COVID-19 treated at a hospital in the Amazon region. Methods: This is a cross-sectional, quantitative, retrospective study, with data from 28 patients, of both sexes, attended between April and August 2020, collected through the analysis of medical records, using an adapted data collection form, considering aspects clinical, epidemiological and laboratory tests. Descriptive and analytical statistics were performed using the BioEstat ${ }^{\circledR} 5.320$ software. After, approval by the Research Ethics Committee. Results: The sample had a mean age of 4.9 years \pm 5 years, with no predominance between genders. The main signs and symptoms found were dyspnea, nausea / vomiting, abdominal pain, cough, runny nose, hand and foot swelling, and diarrhea. Among the laboratory alterations, there was an increase in troponin (100\%), D-dimer, ESR (96\%), hypertriglyceridemia (95\%), a decrease in hemoglobin (96\%), a decrease in HDL (81\%), an increase in TGP $(76.9 \%)$ and ferritin (76.9\%). Conclusion: It is concluded that there is no predominance between genders, with a wide age range, with the most frequent clinical manifestations being respiratory and gastrointestinal. The main laboratory findings reflect high inflammatory activity and the systemic character of the disease.
\end{abstract}

Key words: Coronavirus, Infection from coronavirus, Systemic inflammatory response syndrome.

\section{RESUMEN}

Objetivo: Describir hallazgos de laboratorio y características clínico-epidemiológicas en niños y adolescentes con Síndrome Inflamatorio Multisistémico Pediátrico (SIM-P) asociado a COVID-19 tratados en un hospital de la región amazónica. Métodos: Se trata de un estudio transversal, cuantitativo, retrospectivo, con datos de 28 pacientes, de ambos sexos, atendidos entre abril y agosto de 2020 , recogidos mediante el análisis de historias clínicas, utilizando un formulario de recogida de datos adaptado, considerando aspectos clínicos, Pruebas epidemiológicas y de laboratorio. La estadística descriptiva y analítica se realizó mediante el software BioEstatß ${ }^{\circledR}$ 5.320. Posteriormente, aprobación por el Comité de Ética

\footnotetext{
${ }^{1}$ Hospital Bettina Ferro de Souza da Universidade Federal do Pará, Belém - PA.

*E-mail: a-carolmacedo@hotmail.com

${ }^{2}$ Fundação Santa Casa de Misericórdia do Pará, Belém - PA.
} 
en Investigación. Resultados: La muestra tuvo una edad promedio de 4.9 años \pm 5 años, sin predominio entre géneros. Los principales signos y síntomas encontrados fueron disnea, náuseas / vómitos, dolor abdominal, tos, secreción nasal, hinchazón de manos y pies y diarrea. Entre las alteraciones de laboratorio, hubo aumento de troponina (100\%), dímero D, VSG (96\%), hipertrigliceridemia (95\%), disminución de hemoglobina (96\%), disminución de HDL (81\%), un aumento de TGP (76,9\%) y ferritina (76,9\%). Conclusión: Se concluye que no existe predominio entre géneros, con un amplio rango de edad, siendo las manifestaciones clínicas más frecuentes las respiratorias y gastrointestinales. Los principales hallazgos de laboratorio reflejan una alta actividad inflamatoria y el carácter sistémico de la enfermedad.

Palabras clave: Coronavirus, Infección por coronavírus, Síndrome de respuesta inflamatoria sistémica.

\section{INTRODUÇÃO}

Em dezembro de 2019 surgiu na China um novo coronavírus, denominado severe acute respiratory syndrome coronavirus (SARS-CoV-2). A doença associada ao SARS-CoV-2 - "coronavirus disease 2019" (COVID-19) - tornou-se o mais grave problema de saúde pública desta geração, tendo sido declarada como uma pandemia, em 11 de março de 2020 (ZHU Z, et al., 2020; ALVIM AS, et al.,2020; MEIRELLES AF, et al.,2020).

A Sociedade de Pediatria do Reino Unido emitiu um alerta aos pediatras relatando a identificação de uma nova apresentação clínica em crianças, possivelmente associada à COVID-19, caracterizada por uma síndrome inflamatória multissistêmica (Mangla SM, 2020). O primeiro relato de caso de uma criança, foi um lactente de 6 meses, com Doença de Kawasaki (DK) e COVID-19 concomitantes, foi publicado nos Estados Unidos em 7 de abril de 2020. A partir de então, foram publicados relatos de casos e séries de casos em outros países da Europa, Estados Unidos e América Latina, de uma SIM-P, grave, que compartilha características clínicas e laboratoriais com a DK (seja típica ou incompleta), síndrome do choque tóxico estafilocócico ou estreptocócico, sepse bacteriana e síndrome de ativação de macrofágica (HENNON TR, et al., 2020; TOUBIANA J, et al., 2020).

A SIM-P é uma doença que envolve pelo menos dois órgãos e sistemas, tais como: cardíaco, renal, respiratório, hematológico, gastrointestinal, dermatológico ou neurológico. O diagnóstico é estabelecido pelos critérios propostos pelo Ministério da Saúde, com base na definição de caso da Organização Mundial da Saúde (OMS), validado pela Sociedade Brasileira de Pediatria, Sociedade Brasileira de Reumatologia, Sociedade Brasileira de Cardiologia e Instituo Evandro Chagas (BRASIL, 2020).

Em uma das primeiras séries de casos do Reino Unido foram reportados oito crianças e adolescentes. Todos eles evoluíram para choque (com hipotensão arterial e taquicardia), principalmente cardiogênico e com elevações de marcadores de função miocárdica (troponina e pró-BNP). Entre as alterações laboratoriais observou-se elevação dos valores de proteína C-reativa (PCR), procalcitonina, ferritina, triglicérides, Ddímero, assim como das enzimas marcadoras de miocardite. Apenas duas crianças tiveram detecção de RNA viral nas amostras de nasofaringe e lavado bronco-alveolar, sendo uma delas a criança que faleceu (a detecção de SARS-CoV-2 foi feita post-mortem) (ZHU Z, et al., 2020; ALVIM AS, et al.,2020).

As principais diferenças entre Doença de Kawasaki (DK) e SIM-P observadas são: em primeiro lugar, a mediana da idade de apresentação é maior do que na DK clássica, com idade mais avançada ( $>5$ anos) como um indicador de possível suporte na UTI. Em segundo lugar, tanto a frequência quanto a gravidade da miocardite são notavelmente diferentes da KD clássica. Terceiro, dor abdominal e/ou diarreia foram relatadas com mais frequência (81\%) do que na DK clássica (aproximadamente um em cada três pacientes). Finalmente, a tempestade de citocinas, refletida clinicamente por insuficiência cardíaca, pneumonia, características gastrointestinais, neurológicas e renais, associada a níveis elevados de PCR, ferritina e citocinas (IL-1, TNFa e IL-6 especialmente), foi mais comum na SIM-P. Esses sinais, além da insuficiência cardíaca, também são comuns em adultos com COVID-19 grave (ZHU Z, et al; TOUBIANA J, et al., 2020).

A desregulação imunológica em adultos com doença respiratória é caracterizada por linfopenia (especificamente células NK, linfócitos T CD4 e linfócitos B) e produção sustentada de citocinas próinflamatórias, como fator de necrose tumoral (TNF- $\alpha$ ) e interleucina IL-6. Na DK, um estado hiperinflamatório 
sistêmico é caracterizado por níveis elevados de TNF, IL-6, IL-1 $\beta$, IL-17 e fator estimulador de colônia de granulócitos. Especula-se que SIM-P é um fenômeno imunológico tardio associado à inflamação após infecção sintomática ou assintomática por COVID-19 (NAKRA NA, et al., 2020).

Diversos mecanismos patofisiológicos são sugeridos como envolvidos na resposta imune de crianças com COVID-19 agudo e aquelas com SIM-P, entre eles, a "imaturidade" do sistema imunológico seria o principal responsável pelos casos leves de COVID-19 observados em crianças. No entanto, o real fator determinante para o desenvolvimento de formas graves de SIM-P, com choque cardiogênico e tempestade de citocinas, ainda não foi completamente compreendido (NAKRA NA, et al., 2020; TOUBIANA J, et al., 2020).

Deste modo, novos estudos são imprescindíveis para ampliar o conhecimento sobre os achados clínicos, epidemiológicos e laboratoriais mais encontrados no decorrer da doença. Através destes dados, preditores de maior gravidade poderão ser identificados e inseridos como coadjuvantes para o reconhecimento e tratamento precoce desses pacientes. No Brasil, em 22/05/2020, o Ministério da Saúde emitiu uma Nota de Alerta sobre a SIMP em crianças e adolescentes associada à COVID-19, pautado nos relatos de casos de outros países, sem registro de números exatos no país (BRASIL, 2020).

Para isso, este estudo propôs identificar os achados clínicos, epidemiológicos e laboratoriais em crianças com SIM-P associada à COVID-19 atendidas em unidade de referência na Amazônia brasileira, de modo a reconhecer o panorama da doença, com dados coletados entre abril e agosto de 2020, descrevendo-os.

\section{MÉTODOS}

Trata-se de uma pesquisa quantitativa, de um estudo transversal, retrospectivo, com dados obtidos a partir de prontuário de 28 pacientes pediátricos atendidos em unidade de referência na Amazônia brasileira, entre abril e agosto de 2020. A casuística deste estudo compreendeu pacientes diagnosticados com SIM-P associada à Covid-19, internados na unidade de Terapia Intensiva Pediátrica (UTI) e na enfermaria de Pediatria, no período referido, disponíveis em arquivo de prontuários da instituição.

Foram incluídos no estudo crianças e adolescentes, menores de 16 anos, do sexo feminino e masculino, diagnosticados com SIM-P associada à Covid-19, segundo critérios da Organização Mundial de Saúde (OMS), independente do desfecho clínico. Sendo excluídos os pacientes com características clínicas de COVID-19 aguda. Os dados foram coletados através da análise de prontuários eletrônicos, usando ficha de coleta de dados adaptada com itens da ficha de notificação obrigatória para casos de SIM-P, do Ministério da Saúde (2020). Todos os resultados foram analisados com base nos valores de referência utilizados pelo laboratório local.

$\mathrm{Na}$ aplicação da estatística descritiva, foram construídos tabelas e gráficos para apresentação dos resultados e calculadas as medidas de posição como média aritmética e desvio padrão armazenados e organizados na forma de gráficos e tabelas, fazendo uso dos programas computadorizados: Microsoft ${ }^{\circledR}$ Office Excel $\AA^{\circledR}$ e Microsoft $\circledast$ Office Word $\AA$ versões 2019. A estatística analítica foi utilizada para avaliar os resultados das variáveis categóricas da amostra através dos Testes G e Qui-Quadrado Aderência para tabelas univariadas e Testes G e Qui-Quadrado Independência para tabelas bivariadas. As estatísticas descritiva e analítica, foram realizadas no software BioEstat ${ }^{\circledR}$ 5.320. Para a tomada de decisão, adotou-se o nível de significância $\alpha=0,05$ ou $5 \%$, sinalizando com asterisco $\left(^{*}\right)$ os valores significantes.

A utilização dos dados foi precedida de autorização prévia para consulta de prontuário do paciente, bem como da aprovação pelo Comitê de Ética em Pesquisa da instituição, número 133161/2020. O estudo foi realizado conforme a Resolução 466/12 do Conselho Nacional de Saúde que regulamenta a pesquisa com seres humanos no país. Não há conflito de interesses e não houve nenhum tipo de auxílio financeiro.

\section{RESULTADOS}

Foram incluídos no estudo 28 pacientes internados em UTI pediátrica e Enfermaria pediátrica, dos quais 13 pacientes $(46,4 \%)$ pertenciam ao sexo feminino e 15 pacientes $(53,6 \%)$ ao sexo masculino, sem diferença significativa entre os sexos $\left({ }^{*} p=0.4839\right)$. Os participantes tinham em média 4,9 anos \pm 5 anos $(<01-11)$, 
sendo grande parte pertencente à faixa etária dos 4 a 9 anos (57,2\%). Entre os dados epidemiológicos, fora analisado o perfil nutricional dos participantes, através do Índice de Massa Corporal (IMC) encontrados nos pacientes no momento da admissão hospitalar, não observando-se diferença significativa $(p=0.7674)$ entre as classes estabelecidas pela Organização Mundial da Saúde. Em 28,6\% dos pacientes faltaram informações para cálculo do IMC (peso ou estatura sem registro em prontuário), $25 \%$ dos pacientes apresentavam-se eutróficos, $14,3 \%$ apresentavam magreza, 17,9\% sobrepeso e 14,3\%, obesidade (Tabela 1).

Tabela 1 - Caracterização dos pacientes atendidos em UTI e enfermaria pediátrica, $n=28$.

\begin{tabular}{|c|c|c|c|}
\hline Perfil sociodemográfico & Frequência & $\%(\mathrm{~N}=28)$ & p-valor \\
\hline Sexo & & & 0,4839 \\
\hline Feminino & 13 & $46,4 \%$ & \\
\hline Masculino & 15 & $53,6 \%$ & \\
\hline Faixa etária & & & 0,2632 \\
\hline$<1$ & 4 & $14,3 \%$ & \\
\hline 1 a 3 & 6 & $21,4 \%$ & \\
\hline 4 a 6 & 8 & $28,6 \%$ & \\
\hline 7 a 9 & 8 & $28,6 \%$ & \\
\hline$>=10$ & 2 & $7,1 \%$ & \\
\hline Mínimo / Média / Máximo & $<0$ & & \\
\hline Classificação nutricional (IMC) & & & 0,7674 \\
\hline Magreza & 4 & $14,3 \%$ & \\
\hline Eutrófico & 7 & $25,0 \%$ & \\
\hline Sobrepeso & 5 & $17,9 \%$ & \\
\hline Obesidade & 4 & $14,3 \%$ & \\
\hline Sem informação & 8 & $28,6 \%$ & \\
\hline
\end{tabular}

Fonte: Macedo AC, et al., 2021.

Quanto à hospitalização, verificamos que $10(35,7 \%)$ dos pacientes tiveram 5 dias entre o início dos sintomas e a hospitalização, com uma média de tempo para o ocorrido de 16 dias +/- 20 (2-60). Dos pacientes hospitalizados, $18(64,3 \%)$ necessitaram de internação em Unidade de Terapia Intensiva, enquanto 10 $(35,7 \%)$ permaneceram em enfermaria $(p=0,1859)$. Entre os pacientes com necessidade de terapia intensiva pediátrica, 8 (44,4\%) permaneceram 6 a 10 dias internados em UTI, tendo-se uma média de permanência de $13,7+/-15$ (1-64) dias. Não houve diferença significativa entre os dados referentes à hospitalização, quanto ao tempo entre o início dos sintomas, necessidade de UTI e tempo de permanência em terapia intensiva (Tabela 2).

Tabela 2 - Distribuição dos pacientes com relação à hospitalização.

\begin{tabular}{cccc}
\hline Dados da Hospitalização & Frequência & $\%$ (N=28) & p-valor \\
\hline Necessidade de internação em UTI & & & 0,1859 \\
\hline Sim & 18 & $64,3 \%$ & \\
Não & 10 & $\mathbf{n}=\mathbf{1 8}$ & 0,5193 \\
\hline Tempo em UTI (dias) & & $22,2 \%$ & \\
\hline 1 a 5 & 4 & $44,4 \%$ & \\
Acima de 10 & 8 & $33,4 \%$ & \\
Mínimo / Média / Máximo & 6 & & 0,5181 \\
\hline Tempo entre início dos sintomas e hospitalização & \multicolumn{3}{c}{$01 / 13.7 / 64$} \\
\hline 1 a 5 & 10 & $35,7 \%$ & \\
6 a 10 & 3 & $10,7 \%$ & \\
11 a 20 & 4 & $7,3 \%$ & \\
Acima de 30 & 4 & $7,1 \%$ & \\
Sem informação & 2 & $14,3 \%$ & \\
Mínimo / Média / Máximo & 2 & & \\
\hline
\end{tabular}

Fonte: Macedo AC, et al., 2021. 
No que tange à distribuição dos principais sinais e sintomas encontrados, destaca-se a ocorrência de dispneia, náuseas e vômitos, dor abdominal, tosse, coriza, edema de mãos e pés, diarreia e exantema/rash como os mais comuns. Porém, não houve diferença estatística significativa entre eles no momento da admissão/notificação do caso (Gráfico 1).

Gráfico 1 - Principais sinais e sintomas no momento da admissão/notificação do caso.

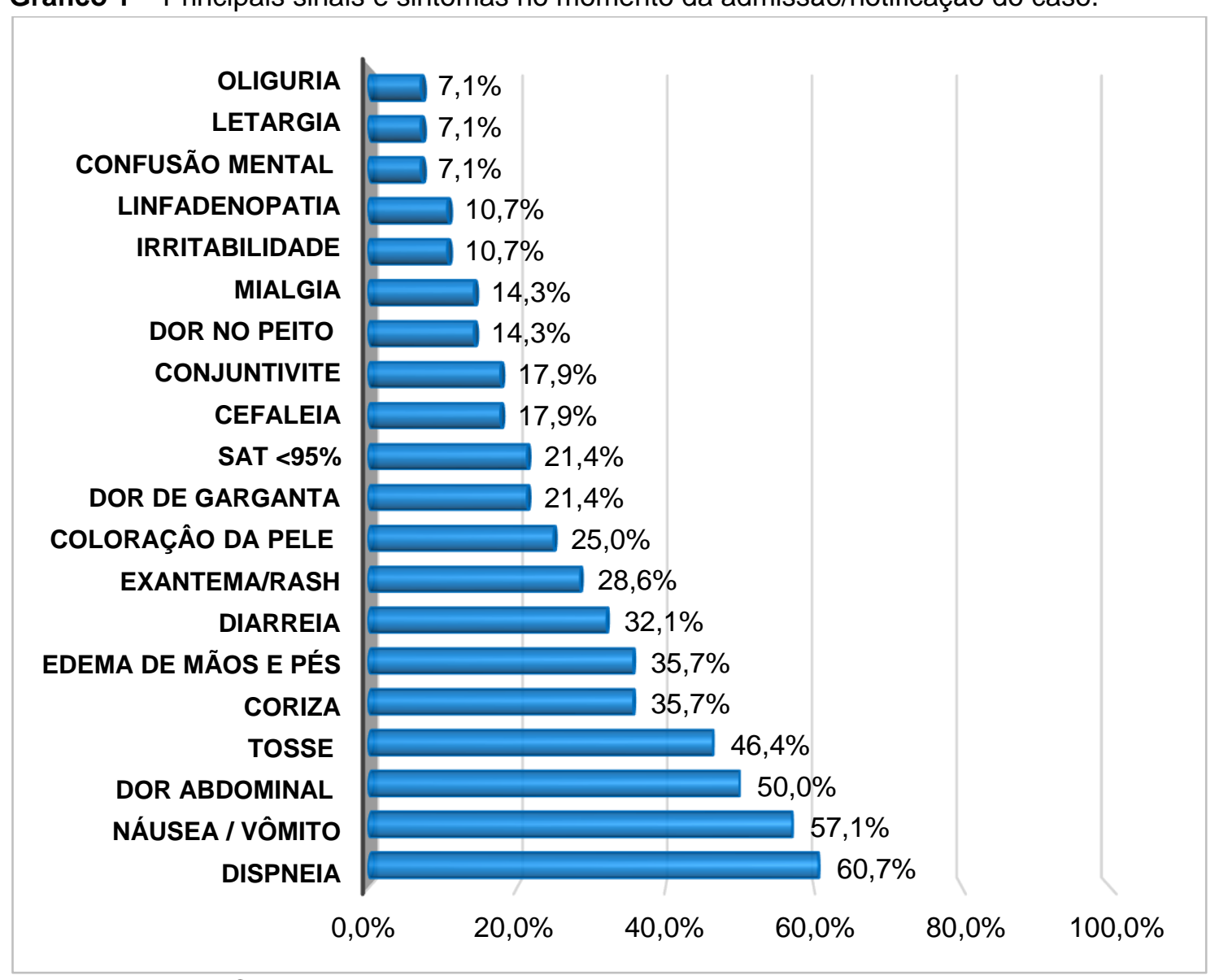

Fonte: Macedo AC, et al., 2021.

Ao serem analisados os exames laboratoriais realizados, considerando os primeiros testes colhidos na admissão ou nos primeiros dias de internação, observa-se diferença estatisticamente significativa de elevação de troponina em 26 pacientes (100\%), que realizaram o exame, elevação de D-Dímero em 25 pacientes (100\%), aumento na VHS em 24 pacientes (96\%), hipertrigliceridemia em 19 pacientes (95\%), queda da hemoglobina em 25 pacientes (96\%), decréscimo do HDL em 17 pacientes (81\%), elevação do TGP em 20 pacientes (76,9\%) e da ferritina em 20 dos pacientes (76,9\%). Nos demais exames, apesar da verificação de alteração, não houve diferença significativa entre os alterados e normais para o limite de referência do laboratório.

No hemograma, além da anemia observada, verificou-se leucocitose com neutrofilia em 17 pacientes (58\%), bem como linfopenia e plaquetose em 10 pacientes (34\%). Entre as demais alterações, 13 pacientes $(46 \%)$ apresentaram lipase aumentadas e apenas 7 pacientes (25\%) apresentaram hipoalbuminemia. Entre os eletrólitos, verificou-se alteração sobretudo nos níveis de potássio, sendo 4 pacientes (14\%) com hipocalemia e outros $3(10 \%)$ com hipercalemia. As alterações de perfil lipídico envolveram hipertrigliceridemia, já referida, bem como níveis diminuídos de HDL com LDL elevado em 7 pacientes (25\%). Nas alterações de fibrinogênio, 6 pacientes apresentaram hipofibrinogenemia (24,4\%) e 6 hiperfibrinogenemia (24,4\%), com 6 pacientes (24,4\%) também apresentando hiperlactatemia (Gráfico 2). 
Gráfico 2 - Distribuição dos exames laboratoriais realizados pelos pacientes à admissão ou evolução de quadro compatível com SIM-P durante internação.

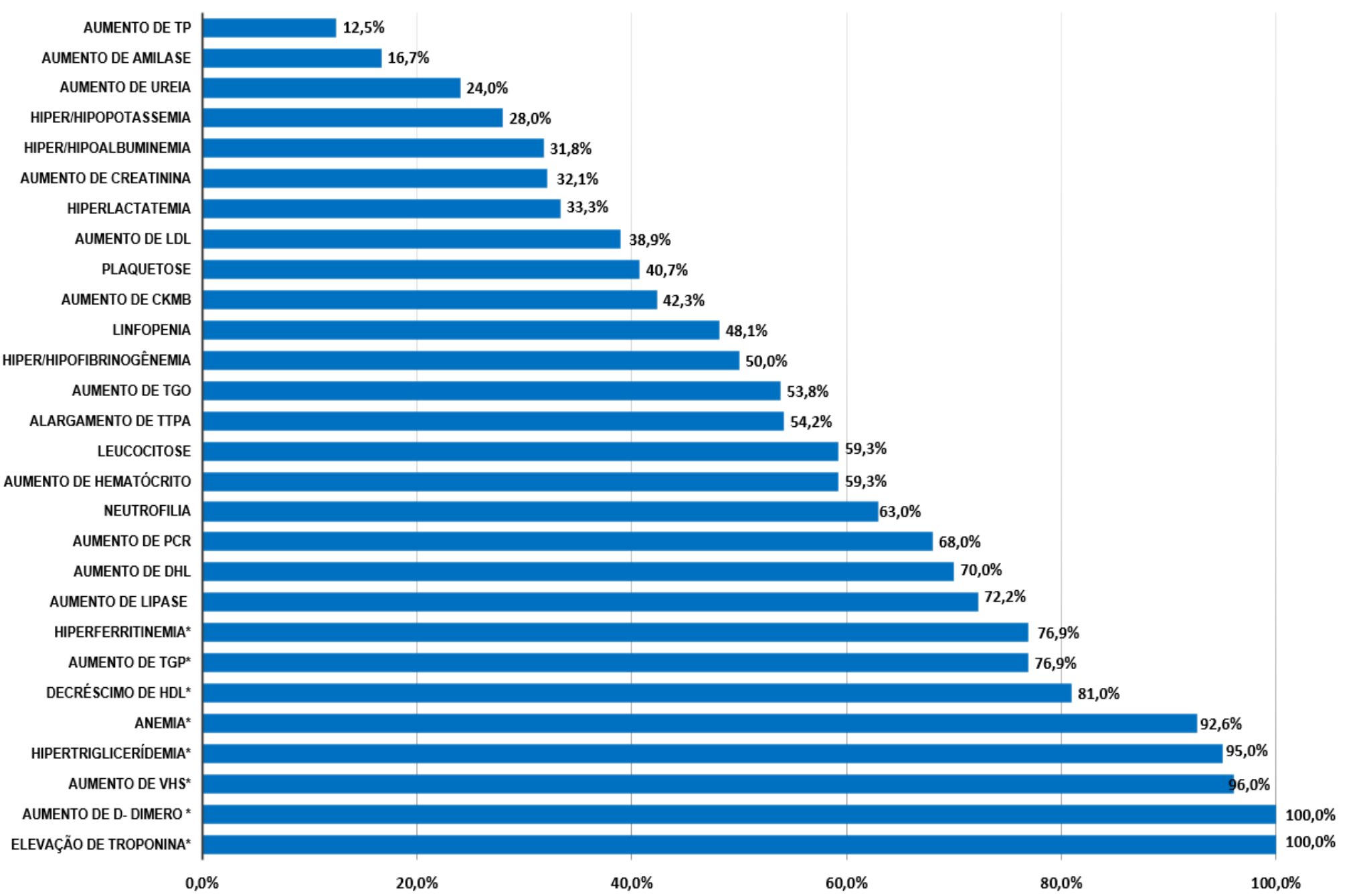

Fonte: Macedo AC, et al., 2021. 
A maioria dos pacientes não apresentava comorbidades à internação, com 21 (75\%) dos pacientes previamente hígidos e 7 pacientes (25\%) com comorbidades, tendo-se uma diferença significativa entre os grupos analisados $(p<0.0001)$.

Ao analisar os pacientes com clínica compatível e história epidemiológica para a infecção pelo Sars-CoV2, observou-se que houve proporção significativa de pacientes que tiveram a reação em cadeia da polimerase reversa (RT-PCR) para COVID-19 negativo ( $p=0,0388)$, com $15(53,6 \%)$ dos pacientes negativos e $4(14,3 \%)$ positivos no momento do exame. Ao passo que, dos 28 pacientes, houve proporção significativa de casos $(p<$ 0.0001 ) que não realizaram os exames de sorologia IgM e $\lg G$ quantitativos e qualitativos. Dos quais 15 $(53,6 \%)$ não realizaram sorologia qualitativa, e $23(82,1 \%)$ não realizaram a pesquisa quantitativa. Mostrandose, portanto, que a maioria teve o caso notificado com base em história epidemiológica e/ou com RT-PCR negativo (Tabela 3).

A maioria teve hemocultura negativa no momento da internação em 24 (85,7\%) dos pacientes. Entre os demais, 2 tiveram hemoculturas positivas para Staphylococcus epidermidis. Deste modo foi possível descartase, no início do protocolo de notificação, outras causas de infecção no momento do diagnóstico.

Tabela 3 - Avaliação dos exames para detecção de COVID-19 (RT-PCR e Sorologia quantitativa e qualitativa).

\begin{tabular}{rccc}
\hline \multicolumn{1}{c}{ Exames para CoVID-19 } & Frequência & $(\mathbf{N}=\mathbf{2 8})$ & p-valor \\
\hline RT-PCR & & & $0.0388^{* *}$ \\
\hline Positivo & 4 & $14,3 \%$ & \\
Negativo* $^{*}$ & 15 & $53,6 \%$ & \\
Não realizado & 9 & $32,1 \%$ & \\
\hline IgM e IgG Qualitativo & & & $<0.0001^{*}$ \\
\hline Não realizado* & 15 & $53,6 \%$ & \\
Reagente & 7 & $25,0 \%$ & \\
Não reagente & 6 & $21,4 \%$ & \\
\hline IgM e IgG Quantitativo & & & $<0.0001^{* *}$ \\
\hline Não realizado* & 23 & $82,1 \%$ & \\
Reagente & 1 & $3,6 \%$ & \\
Não reagente & 4 & $14,3 \%$ & \\
\hline
\end{tabular}

Legenda: *Teste Qui-Quadrado Aderência; **Teste G Aderência.

Fonte: Macedo AC, et al., 2021.

Dentre os pacientes estudados, 9 (32,1\%) apresentavam critérios para Doença de Kawasaki (DK) completa e 2 pacientes $(7,1 \%)$ apresentaram critérios para Síndrome de Ativação Macrofágica (SAM). Em relação as comorbidades, observou-se a ocorrência de Doença do Refluxo Gastresofágico (DRGE), Encefalopatia Crônica Não Evolutiva (ECNE), Desnutrição Energético Proteica Grave (DEP Grave), Encefalite, Hidrocefalia extrema, Síndrome Nefrótica e Transtorno do Déficit de Atenção e Hiperatividade (TDAH).

Entre as complicações, 8 pacientes (28\%) necessitaram de Ventilação Mecânica Invasiva (VMI), 8 (28\%) apresentaram choque cardiogênico com necessidade de uso de drogas vasoativas, 7 (25\%) tiveram pneumonia secundária, 5 (17\%) complicaram com episódios convulsivos, $3(10,7 \%)$ tiveram eventos tromboembólicos graves. Outras complicações observadas durante internação foram: hipertensão arterial, parada cardiorrespiratória, insuficiência renal aguda (IRA), edema agudo de pulmão, linfonodomegalia 
profunda, miocardite, aneurisma coronariano, arritmia cardíaca, endocardite e insuficiência cardíaca congestiva.

Finalizando a coleta de dados, verificou-se que proporção significativa dos casos recebeu alta hospitalar (92,9\% dos pacientes), com ocorrência de 2 óbitos (7,1\%). Dentre os pacientes que receberam alta, 18 $(69,2 \%)$ necessitaram de acompanhamento em ambulatório de Cardiologia Pediátrica e Reumatologia Pediátrica, devido aos achados ecocardiográficos e clínicos com necessidade de avaliação seriada pós internação, descritos como "Alta com sequelas" (Tabela 4).

Tabela 4 - Evolução dos pacientes para alta ou óbito.

\begin{tabular}{|c|c|c|c|}
\hline Evolução do paciente & Frequência & $\%(\mathbf{N}=28)$ & p-valor \\
\hline Evolução & & & $<0.0001^{*}$ \\
\hline Alta* & 26 & $92,9 \%$ & \\
\hline Óbito & 2 & $7,1 \%$ & \\
\hline Tipo de alta & & $n=26$ & $0.0499^{\star}$ \\
\hline Com sequela** & 18 & $69,2 \%$ & \\
\hline Sem sequela & 8 & $30,8 \%$ & \\
\hline
\end{tabular}

Fonte: Macedo AC, et al., 2021.

\section{DISCUSSÃO}

A infecção pelo SARS-CoV-2 e a pandemia pela COVID-19 trouxe preocupações acerca do acometimento, grave e fatal da doença, principalmente em adultos. Porém, o aumento do número de crianças com manifestações tardias graves de COVID-19 exigindo internação na UTIP foi observada em várias regiões à nível global (TOUBIANA J, et al., 2020). Neste estudo, realizado no centro de referência materno-infantil, na Amazônia brasileira, incluímos 28 pacientes com menos de 16 anos de idade, que preencheram os critérios para SIM-P associado à infecção por SARS-CoV-2 com base em critério diagnóstico proposto pelo Ministério da Saúde e Organização Mundial da Saúde, encaminhadas da capital e do interior do estado.

A maioria dos pacientes apresentou infecção pelo SARS-CoV-2 documentada com exames (sorologia, teste rápido ou RT-PCR) ou história epidemiológica recente para a doença, e grande parte não tinha doenças subjacentes documentadas, não sendo observado predominância entre os sexos, como descrito em estudos internacionais (CONSIGLIO CR, et al., 2020; HENDERSON LA, et al., 2020).

Entretanto, não observamos doenças predisponentes, visto que houve um número pequeno de pacientes com comorbidades. Achado este comparável com outra série de casos do Reino Unido, Itália, França e Suíça, em que entre 70 crianças afetadas a maioria não tinha comorbidades subjacentes além de que, algumas crianças apresentaram abdome cirúrgico agudo e foram submetidas a laparotomia exploradora, com achados intraoperatórios de linfadenite mesentérica e peritonite (CONSIGLIO CR, et al., 2020). De fato, a dor abdominal tem se mostrado um sintoma frequente, presente em cerca de metade dos nossos pacientes.

Uma limitação deste estudo foi o pequeno tamanho da amostra, embora o presente levantamento tenha incluído um número maior de pacientes que a média dos estudos brasileiros (PEREIRA MFB, et al., 2020). A faixa etária predominante foi compreendida de indivíduos entre 4 e 9 anos, o que confirma a distribuição de idade ampla, com relatos de SIM-P encontrados em crianças variando de 3 a 17 anos (WHITTAKER E, et al., 2020; HENDERSON LA, et al., 2020). O quadro clínico foi variado, sendo sobretudo representado por sintomas gastrointestinais e aqueles associados à DK (completa ou incompleta), compatível com dados das crianças brasileiras publicadas anteriormente (PEREIRA MFB, et al., 2020). Achados que ratificam a 
importância de tais sinais e sintomas na composição dos critérios diagnósticos atualmente propostos (BRASIL, 2020).

Em relação aos achados laboratoriais, níveis de troponina, elevação de D-Dímero, VHS, e da ferritina, além de hipertrigliceridemia, anemia e elevação das transaminases demonstram não só a alta atividade inflamatória, como também o acometimento sistêmico da doença. Tais achados também descritos em estudos brasileiros e internacionais (LUVIDGSSON JF, et al., 2020; PEREIRA MFB, et al., 2020; HENDERSON LA, et al., 2020; FELDSTEIN LR, et al., 2020). Embora, não tenham sido identificados em nosso estudo, hipoalbuminemia e a trombocitopenia tem sido descritos na maioria dos trabalhos publicados (WHITTAKER E, et al., 2020; HENDERSON LA, et al., 2020).

Os valores laboratoriais de marcadores de lesão miocárdica no momento do diagnóstico, especificamente os níveis de troponina T e peptídeo natriurético do tipo B (BNP)/ N-terminal proBNP (NT-proBNP), podem ajudar a identificar pacientes com risco de acometimento cardíaco resultante de SIM-P (WHITTAKER E, et al., 2020; HENDERSON LA, et al., 2020). Porém, tais exames não estão disponíveis na prática clínica de todos os serviços de referência, não fazendo parte da realidade da maioria dos hospitais brasileiros. Da mesma forma, existe dificuldade na análise dos níveis de procalcitonina (que poderiam estar elevados na ausência de infecção bacteriana), sugerido pela American College of Rheumatology. Porem exames mais acessíveis, como a dosagem de DHL, tem grande valor na detecção de lesão tecidual, também observado em nosso estudo.

Até o momento, não há dados claros que indiquem o valor preditivo positivo ou negativo para cada sintoma clínico ou alteração laboratorial no diagnóstico de SIM-P. Mesmo assim, a American College of Rheumatology define como necessário que o primeiro passo no diagnóstico laboratorial deve incluir estudos de laboratório que são facilmente obtidos na maioria dos serviços, como hemograma, painel metabólico completo, VHS, medição da Proteina C Reativa (PCR), teste de SARS-CoV-2 por reação em cadeia da polimerase [PCR] ou sorologia. Assim, para dar seguimento no diagnóstico, as crianças devem ter VHS e/ou PCR elevados e pelo menos uma outra característica laboratorial sugestiva: linfopenia, neutrofilia, trombocitopenia, hiponatremia ou hipoalbuminemia.

Ao diagnóstico da infecção pelo SARS-CoV-2, é sabido que o teste sorológico produziu resultados positivos em uma proporção maior de pacientes SIM-P em comparação com os resultados do teste de RTPCR e, portanto, ambos devem ser usados para avaliar a ligação epidemiológica à infecção (HENDERSON LA, et al., 2020). Outro ponto para discussão no presente estudo foi a não realização de nenhum teste diagnóstico por alguns dos pacientes, ou a perda dos dados após transferência entre os municípios e o atendimento neste serviço de referência, justificando-se a utilização de dados clínicos e epidemiológico (contato com adultos com COVID-19) para tal diagnóstico.

A verdadeira incidência de SIM-P permanece desconhecida. Como as crianças geralmente apresentam sintomas leves de COVID-19 e são testadas com menos frequência do que os adultos, a incidência de SIM$P$ entre crianças infectadas com SARS-CoV-2 não é clara. É crucial estabelecer vigilância para casos, particularmente em comunidades com níveis mais altos de transmissão de SARS-CoV-2, como sugerem os estudos atuais (KAUSHIK AMD, et al., 2020).

Devido às limitações de uma revisão retrospectiva de prontuários e testes clínicos, não fomos capazes de avaliar com precisão o tempo de início da infecção por SARS-CoV-2 ou a influência de resultados falsos negativos nos testes respiratórios, nem fomos capazes de testar amostras não respiratórias, incluindo fezes. Do mesmo modo, as descrições nacionais e internacionais desta Síndrome associada à COVID-19 ainda estão em andamento, o que provoca a necessidade de mais estudos a cerca desse tema.

\section{CONCLUSÃO}

Nesta série de casos de crianças hospitalizadas que preencheram os critérios para SIM-P, não houve predomínio entre os sexos, com faixa etária ampla de acometimento. As manifestações clínicas mais frequentes foram as respiratórias, gastrointestinais e sinais presentes na DK. Os principais achados 
laboratoriais incluem anemia, leucocitose com neutrofilia e linfopenia, além da elevação de troponina, DDímero, VHS, TGP e da ferritina, que refletem alta atividade inflamatória e o caráter sistêmico da doença.

\section{REFERÊNCIAS}

1. ALVIM AS, et al. Síndrome inflamatória multissistêmica em crianças e adolescentes com COVID-19: uma revisão de literatura. Journal of Infection Control. 2020; 9(3).

2. CHEUNG EW, et al. Síndrome inflamatória multissistêmica relacionada ao COVID-19 em crianças e adolescentes previamente saudáveis na cidade de Nova York. JAMA. 2020; 324: 294-296.

3. BRASIL. Ministério da Saúde. Nota Técnica N. 16/2020 CGPNI/ DEIDT/SVS/MS: Orientações sobre a notificação da Síndrome Inflamatória Multissistêmica (SIM-P) temporalmente associada à COVID-19. OFÍCIO CIRCULAR № 133/2020/SVS/MS de 24 de julho de 2020.

4. CONSIGLIO CR, et al. The Immunology of Multisystem Inflammatory Syndrome in Children with COVID-19. Cell. 2020; 183(4): 968-981.e7.

5. FARIAS ECF, et al. "Multisystem Inflammatory Syndrome Associated With Coronavirus Disease in Children: A Multicentered Study in Belém, Pará, Brazil." The Pediatric infectious disease journal vol. 39,11 (2020): e374-e376.

6. FARIAS ECF, et al. Síndrome inflamatória multissistêmica em criança associada à doença coronavírus 19 na Amazônia brasileira: desfecho fatal em lactente. Revista Paulista de Pediatria. 2021; 39: e 2020165.

7. FELDSTEIN LR, et al. "Multisystem Inflammatory Syndrome in U.S. Children and Adolescents." The New England journal of medicine vol. 383,4 (2020): 334-346.

8. HENDERSON LA, et al. "American College of Rheumatology Clinical Guidance for Multisystem Inflammatory Syndrome in Children Associated With SARS-CoV-2 and Hyperinflammation in Pediatric COVID-19: Version 1." Arthritis \& rheumatology (Hoboken, N.J.) vol. 72,11 (2020): 1791-1805.

9. HENNON TR, et al. COVID-19 associated Multisystem Inflammatory Syndrome in Children (MIS-C) guidelines; a Western New York approach. Prog Pediatr Cardiol. 2020;

10. KAUSHIK AMD, et al. Uma revisão sistemática da síndrome inflamatória multissistêmica em crianças associada à infecção por SARS-CoV-2, The Pediatric Infectious Disease Journal: novembro de 2020 - Volume 39 - Edição 11 - $p$ e340-e34.

11. LUDVIGSSON JF. A revisão sistemática do COVID - 19 em crianças mostra casos mais leves e um prognóstico melhor do que em adultos. Acta Paediatr. 2020; 109 (6): 1088-95.

12. MANGLA SM. Multisystem Inflammatory Syndrome in Children (MIS-C) - Recent Updates. Indian Pediatr. 2020 Nov 02.

13. MEIRELLES AF, et al. COVID-19 e Saúde da Criança e do Adolescente. Instituto Nacional de Saúde da mulher, da criança e do adolescente. 2020;

14. MONTEL LM, et al. Complicações atípicas e características clínico-epidemiológicas do COVID-19: uma revisão integrativa. Revista Eletrônica Acervo Saúde. 46 (maio 2020), e3699.

15. NAYKRA NA, et al. Multi-System Inflammatory Syndrome in Children (MIS-C) Following SARS-CoV-2 Infection: Review of Clinical Presentation, Hypothetical Pathogenesis, and Proposed Management. Children (Basel). 2020; 7(7): 69.

16. Organização Mundial da Saúde. Doença por coronavírus 2019 (COVID-19). Relatório de situação 57. 2020. Genebra: OMS.

17. PEREIRA, MR et al. Severe clinical spectrum with high mortality in pediatric patients with COVID-19 and multisystem inflammatory syndrome. Clinics, São Paulo, v. 75, e2209, 2020. Epub Aug 19, 2020.

18. POULETTY $M$, et al. Paediatric multisystem inflammatory syndrome temporally associated with SARS-CoV-2 mimicking Kawasaki disease (Kawa-COVID-19): a multicentre cohort. Ann Rheum Dis. 2020;79(8):999-1006.

19. TOUBIANA J, et al. Kawasaki-like multisystem inflammatory syndrome in children during the covid-19 pandemic in Paris, France: prospective observational study. BMJ. 2020;369: m2094. Published 2020 Jun 3.

20. WHITTAKER E, et al. Características clínicas de 58 crianças com síndrome multissistêmica inflamatória pediátrica temporariamente associada à SARS-CoV-2. JAMA 2020; 324: 259-69.

21. ZHU Z, et al. A novel coronavirus from patients with pneumonia in China, 2019. New England Journal of Medicine. 2020 Feb 20; (382). 